\title{
Enhancement of Aqueous Solubility and Oral Bioavailability of Nelfinavir by Complexation with $\beta$ - Cyclodextrin
}

\author{
Shilpi Kumari ${ }^{1}$, Ganesh T Bhawar ${ }^{2}$, Prashant B Musmade ${ }^{2}$ and Shaila Lewis ${ }^{1 *}$ \\ ${ }^{1}$ Department of Pharmaceutics, ${ }^{2}$ Department of Pharmaceutical Quality Assurance, Manipal College of Pharmaceutical \\ Sciences, Manipal University, Manipal 576 104, India
}

*For correspondence: Email: s.lewis@manipal.edu; Tel: +91 8202922482; Fax: +91 8202571998

Received: 15 July 2014

Revised accepted: 10 June 2015

\begin{abstract}
Purpose: To determine if complexation with $\beta$ - cyclodextrin $(\beta-C D)$ increases water solubility and subsequent bioavailability of nelfinavir mesylate (NM).

Methods: Complexation of NM with $\beta-C D$ in 1:1.5 molar ratio was carried out by solvent evaporation, freeze-drying and kneading methods. The complexes were characterized by Fourier transform infrared spectroscopy (FTIR). The in vitro solubility of the pure drug as well as that of the complexes was evaluated using USP type 2 apparatus. One of the drug complexes was also evaluated in vivo using Wistar rats to determine its pharmacokinetic profile.

Results: Freeze-dried NM- $\beta C D$ complex was selected for in vivo studies based on its free flowing property and superior texture. The complexes prepared by the three methods all showed largely similar dissolution rate. The in vivo pharmacokinetic study of the freeze-dried complex in male Wistar rats showed significant increase in Cmax, tmax and AUC $(p \leq 0.05)$ compared to those of the plain drug. Conclusion: These findings suggest that complexation of $N M$ with $\beta-C D$ is an effective and promising approach to increasing the oral bioavailability of NM.
\end{abstract}

Keywords: $\beta$-Cyclodextrin, Nelfinavir mesylate, Inclusion complex, Freeze-drying, Bioavailability, Dissolution, Kneading

Tropical Journal of Pharmaceutical Research is indexed by Science Citation Index (SciSearch), Scopus, International Pharmaceutical Abstract, Chemical Abstracts, Embase, Index Copernicus, EBSCO, African Index Medicus, JournalSeek, Journal Citation Reports/Science Edition, Directory of Open Access Journals (DOAJ), African Journal Online, Bioline International, Open-J-Gate and Pharmacy Abstracts

\section{INTRODUCTION}

Nelfinavir mesylate (NM) is an HIV (human immunodeficiency virus) protease inhibitor which results in production of immature, non-infectious virus during the replication and release life cycle of the virus [1]. Compared to all other protease inhibitors, NM is usually prescribed at a higher than required dose of $1250 \mathrm{mg}$ twice daily for adults [2]. A major drawback in therapeutic application and efficacy of NM in oral administration is its poor water solubility, resulting in poor bioavailability.
Orally administered drugs are assigned the Biopharmaceutics Classification System (BCS) on the basis of solubility and permeability characteristics. NM is a BCS class IV drug [3]. Efforts are in progress to increase its solubility and thereby NM's bioavailability to reduce its dose [4].

Cyclodextrins have been extensively studied with the aim of improving solubility, dissolution and bioavailability of poorly soluble drugs. Cyclodextrins have an internal cavity resembling a truncated cone. The special feature of a 
cyclodextrin is that its internal cavity is hydrophobic while the entrance of the cavity is hydrophilic. Due to this feature, drug molecules complexed with cyclodextrins have increased water solubility [5]. This feature can also alter the physicochemical properties of guest molecules [6]. Enhanced bioavailability with cyclodextrin is observed due to its drug entrapment property [7]. Entrapped drugs are more stable in the form of complexes due to this added protection from the external environment [8].

Of all cyclodextrins, $\beta-C D$ is the most widely used for increasing water solubility of otherwise hydrophobic drugs. The ease of its synthesis and low price are key factors for its popularity [9]. Cyclodextrin complexation of NM with $\beta-C D$ using diverse methods such as solvent evaporation, kneading and ball milling have resulted in increased solubility of NM [10,11]. However, these studies have not addressed NM's pharmacokinetic profile including bioavailability. The present study uses the freeze drying and other methods to prepare NM- $\beta C D$ complexes, and reports the results of its water solubility and pharmacokinetic profile.

\section{EXPERIMENTAL}

\section{Materials}

Nelfinavir mesylate was received as a gift sample from Aurobindo Pharma, Hyderabad, India. Diazepam was procured from INTAS Lab Pvt Ltd, Ahmedabad, India. $\beta$-Cyclodextrin was obtained from Hetero Labs Ltd, Bangalore, India. Acetonitrile and methanol (HPLC grade) were procured from Merck Laboratories Pvt Ltd, Mumbai, India. All other reagents and solvents used were of analytical grade.

\section{Solubility studies}

The solubilities of $\mathrm{NM}$ and $N M / \beta-C D$ mixture were determined between $\mathrm{pH} 1.2$ and 7.4 by shake-flask method. For the same, an excess amount of NM or NM $\beta-C D$ was placed in $10 \mathrm{ml}$ vials to which $3.0 \mathrm{ml}$ of different solutions $(\mathrm{pH}$ 1.2, 4.5, 6.8 and 7.4) and distilled water were added. These vials were incubated in a shaking water bath (orbital shaker incubator, Remi Laboratory instruments, India) set at $150 \mathrm{rpm}$ for $24 \mathrm{~h}$ at $37{ }^{\circ} \mathrm{C}$. Thereafter, samples were centrifuged in an Eppendorf Centrifuge Model 5043 at $23,000 \times \mathrm{g}$ for $15 \mathrm{~min}$ to separate the solid material from the solution and analysed by HPLC after appropriate dilution.[12].

\section{Preparation of NM $\beta-C D$ complex}

Inclusion complex of NM and $\beta-C D$ was prepared in 1:1.5 molar ratio of $\mathrm{NM}$ and $\beta-\mathrm{CD}$ based on the phase solubility study reported by Vavia et al [11]. For the phase solubility study, excess of NM (in quantities exceeding its aqueous solubility) was added to aqueous solutions containing different concentrations of $\beta-C D$ ranging from 2 $\mathrm{mM}$ to $15 \mathrm{mM}$. The mixtures were mechanically stirred at $200 \mathrm{rpm}$ for $48 \mathrm{~h}$ at room temperature followed by filtration through $0.2 \mu \mathrm{m}$ filter and evaluated for NM content using UV spectrophotometry. The apparent stability constant $\mathrm{K}$ was estimated from straight line of phase solubility plot according to the equation of Higuchi and Connars (Eq 1) [13].

$\mathrm{K}=$ Slope/S(1-Slope)

where $S$ is the solubility of NM in the absence of $\beta-C D$.

\section{Co-evaporation method}

The complex (NC-01) was prepared in 1:1.5 molar ratio of NM and $\beta-C D$. A solution of $\beta-C D$ was prepared by dissolving $\beta-C D(1702 \mathrm{mg})$ in water. NM (666 mg) solution was prepared in methanol. The NM solution and $\beta-C D$ solution were then mixed together. The solution was stirred magnetically for $1 \mathrm{~h}$ at $70-80{ }^{\circ} \mathrm{C}$ and dried to obtain a powder. The precipitated complex was pulverised, sieved (\# 60) and stored in a desiccator $[14,15]$.

\section{Freeze-drying method}

The freeze-dried product (NC-02) was prepared by dissolving $\beta-C D$ (4256 mg) in water and adding the stoichiometric amount of NM (1667 $\mathrm{mg}$ ). The resulting solution was frozen and freeze dried at $-45{ }^{\circ} \mathrm{C}$ and $45 \mathrm{~m}$ Torr for $48 \mathrm{~h}$. The lyophilized powder was stored in tightly sealed container inside a desiccator until use [16].

\section{Kneading method}

$\beta-C D(N C-03,4256 \mathrm{mg}$ ) was placed in a mortar and wetted with ethanol-water mixture $(1: 1 \mathrm{v} / \mathrm{v})$. Trituration was continued and it was kneaded to a paste consistency. NM (1667 mg) was added and kneaded for 60 min with successive addition of ethanol-water mixture to obtain the desired paste consistency. The formed complex was dried in vacuum oven for $24 \mathrm{~h}$ at $50{ }^{\circ} \mathrm{C}$. Dried product was scraped, passed through a $60 \#$ mesh sieve and stored in a desiccator until further use $[14,16,17]$. 


\section{Fourier Transform Infrared Spectroscopy (FTIR)}

FTIR spectra of the selected complex NC-02) were recorded on a FTIR 8300 Spectrophotometer (Shimadzu, Japan) by $\mathrm{KBr}$ disk method. The scanning range was 4000 to $400 \mathrm{~cm}^{-1}$.

\section{In vitro dissolution studies}

In vitro dissolution studies of the plain NM and the complexes were carried out using USP Type II dissolution apparatus (Electrolab, India). Dissolution of powders equivalent to $10 \mathrm{mg}$ of $\mathrm{NM}$ was studied in $0.1 \mathrm{~N} \mathrm{HCl}$. Dissolution medium $(900 \mathrm{ml})$ was taken and maintained at $37.0 \pm 5^{\circ} \mathrm{C}$. Paddles were rotated at $50 \mathrm{rpm}$. Samples were removed at different time intervals, filtered through Whatman filter paper and analysed for percent drug release by HPLC.

\section{HPLC analysis of NM}

The analytical method for NM was developed and validated as per the ICH Q2 (R1) guideline [18]. Chromatographic separations were performed on a Shimadzu 10 ADVP high performance liquid chromatographic instrument with Grace Smart C $18(250.0 \times 4.6 \mathrm{~mm}, 5 \mu)$ column in isocratic reverse phase mode integrated with UV detection at $254 \mathrm{~nm}$. Mobile phase consisting of a mixture of acetonitrile and $25.0 \mathrm{mM} \mathrm{KH}{ }_{2} \mathrm{PO}_{4} \mathrm{pH} 3.2(50: 50 \% \mathrm{v} / \mathrm{v})$ pumped at a constant flow rate $1.0 \mathrm{ml} / \mathrm{min}$ for the run time of $8.0 \mathrm{~min}$. The injection volume was $20.0 \mu \mathrm{l}$.

Bioanalytical method was also developed and validated as per $\mathrm{ICH}$ guidelines. The analytical conditions were almost similar except mobile

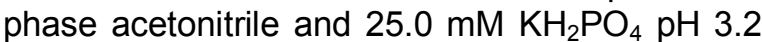
$(45: 55 \% \mathrm{v} / \mathrm{v})$ for the run time of $14.0 \mathrm{~min}$ and injection volume was $50.0 \mu \mathrm{l}$

Retention time for Nelfinavir as well as internal standard diazepam was $8.03 \pm 0.01 \mathrm{~min}$ and $11.45 \pm 0.03 \mathrm{~min}$, respectively. The column and HPLC system were kept at ambient temperature $\left(25^{\circ} \mathrm{C}\right)$.

\section{Pharmacokinetic studies}

A single-dose pharmacokinetic study was conducted in accordance with the ethical guidelines for investigations in laboratory animals and was approved by the Institutional Animal Ethics Committee (IAEC), Manipal University (MU) No: IAEC/KMC/50/2012. Male Wistar rats,
$250 \pm 20 \mathrm{~g}$ were divided into three groups $(n=6)$ each and fasted overnight with free access to water for $12 \mathrm{~h}$. The first group was dosed orally with $20.0 \mathrm{mg} \mathrm{kg}^{-1}$ body weight of NM suspended in $0.5 \%(\mathrm{w} / \mathrm{v})$ carboxyl methyl cellulose (CMC) aqueous solution as vehicle. The second group received NM- $\beta-C D$ equivalent to $20.0 \mathrm{mg} \mathrm{kg}^{-1}$ $\mathrm{NM}$ in $0.5 \% \mathrm{CMC}$ solution as vehicle and the third group received $5.0 \mathrm{mg} \mathrm{kg}^{-1} \mathrm{NM}$ in $40 \% \mathrm{v} / \mathrm{v}$ polyethylene glycol and $10 \%$ in ethanol in water for injection administered intravenously to obtain the absolute bioavailability. Blood samples were collected at predetermined time intervals. Plasma was separated immediately by centrifugation at $2500 \mathrm{x} \mathrm{g}$ for $10 \mathrm{~min}$ and frozen at $-20^{\circ} \mathrm{C}$ until analysis.

Various pharmacokinetic parameters were calculated using WinNonlin 5.3.2. For the calculation of oral bioavailability the mean area under the plasma concentration verses time curves AUCO-t was compared. Absolute bioavailability of NM from NM- $\beta-C D$ was obtained as in Eqs 2 -4.

$F=A 1 D 2 / A 2 D 1$

$\mathrm{A} 1=\mathrm{AUC} 0-\infty$ oral, $\mathrm{A} 2=\mathrm{AUC} 0-\mathrm{iv}$

D1 $=$ Dose oral, D2 = Dose iv

where $F$ is the absolute bioavailability

Difference in the pharmacokinetic parameters of NM was evaluated using unpaired t-test $(p=$ $0.05)$ with graph pad prism. Results are expressed as mean value \pm SEM.

\section{Extraction of drug from plasma}

The bioanalytical method was validated as per FDA guidelines. The plasma concentration of NM was determined by RP-HPLC. Ten $\mu \mathrm{L}$ of diazepam (I.S.) solution $\left(40 \mu \mathrm{g} \mathrm{mL}^{-1}\right)$ was added to $90 \mu \mathrm{L}$ plasma standard or sample followed by $200 \mu \mathrm{L}$ of $50 \mathrm{mM}$ potassium dihydrogen phosphate buffer of $\mathrm{pH}$ 3.2. The sample was vortexed for $30 \mathrm{~s}$ and the drug was extracted by addition of $1.8 \mathrm{ml}$ of TBME (Tertiary butyl methyl ether). The mixture was once again vortexed and centrifuged at $2500 \times \mathrm{g}$ for $10 \mathrm{~min}$. The organic phase was collected and evaporated to dryness at $55{ }^{\circ} \mathrm{C}$ under a gentle stream of nitrogen. The dried residue was reconstituted with $200 \mu \mathrm{L}$ of

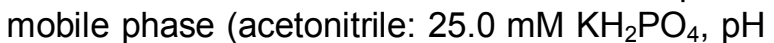
$3.2(50: 50 \% \mathrm{v} / \mathrm{v})$ and vortexed for $1 \mathrm{~min}$. The supernatant was collected into a $250 \mu \mathrm{L}$ vial- 
insert and $50 \mu \mathrm{L}$ was injected into the HPLC system.

\section{RESULTS}

\section{Selection of complex}

Complexes obtained by solvent evaporation (NC01) and kneading method (NC-03) were in the form of lumps and off white in color. In case of freeze dried product (NC-02) texture was free flowing and white in color. Hence, NC-02 was selected for further studies based on its superior texture and appearance.

\section{FTIR spectra}

IR spectra of Inclusion complex (NC-02) is shown in Fig. 1. Observation of the IR spectra clearly indicates that the shape and intensity of peaks of NM are largely affected when it is complexed with $\beta-C D$. The essential peaks of Nelfinavir have been shifted, and there was an intense broad peak at $3379.40 \mathrm{~cm}^{-1}$ indicating possible $\mathrm{H}$ bonding between $\mathrm{NM}$ and $\beta-\mathrm{CD}$.

\section{In vitro dissolution}

Rapid cumulative release of $75-90 \%$ was observed within 5 min with the NM $\beta C D$; this is very high compared to plain NM drug which released only $40 \%$ in $90 \mathrm{~min}$. NC-01-87 \%, NC02- $95 \%$, NC-03- $98 \%$ release in 5 min. All the complex formation approaches improved in vitro dissolution.

\section{Solubility of drug and $\beta$-CD-drug complex (NC-02)}

As NM is a basic drug, it shows ionization in acidic medium and is therefore soluble in low $\mathrm{pH}$ solutions. Our results also showed highest solubility at $\mathrm{pH} 1.2$ when compared with other buffers of higher $\mathrm{pH}$. However, highest solubility was observed in water as NM is in salt form.

From the solubility study of both drug as well as Inclusion complex, it is clear that there has been significant increase in the solubility of drug in water (4.63 fold), $\mathrm{pH} 1.2$ (5.32 fold) and $\mathrm{pH} 4.5$ (3.64 fold) as seen in Fig 2.

\section{Pharmacokinetic profile}

The plasma concentration - time profile of orally administered $\mathrm{NM}$ in $0.5 \%$ carboxy methyl cellulose suspension and in combination with $\beta$ $C D$ is shown in Figures 3 and 4 while corresponding pharmacokinetic parameters are summarized in Table 1.

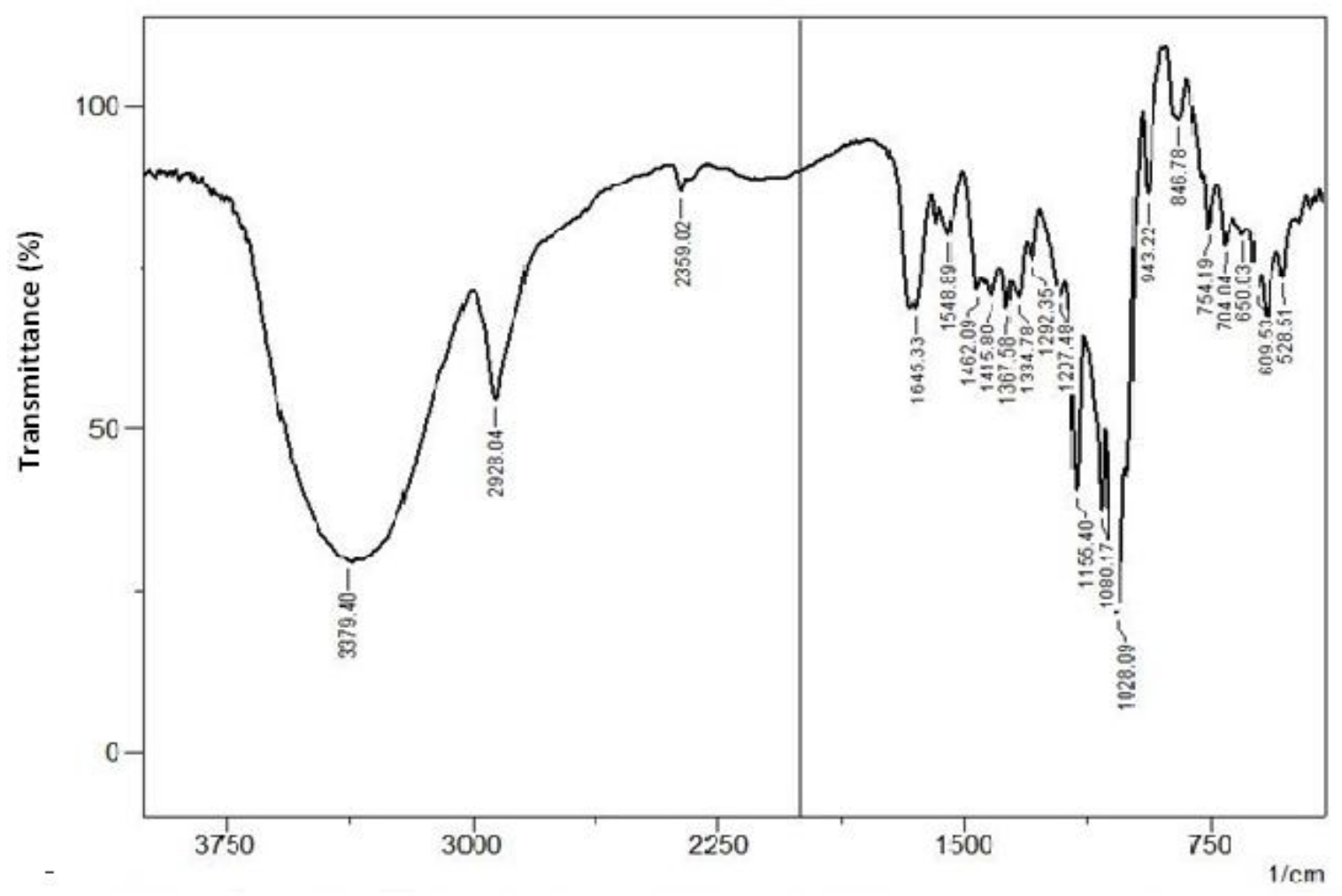

Fig 1: IR spectra of inclusion complex (NC-02) 


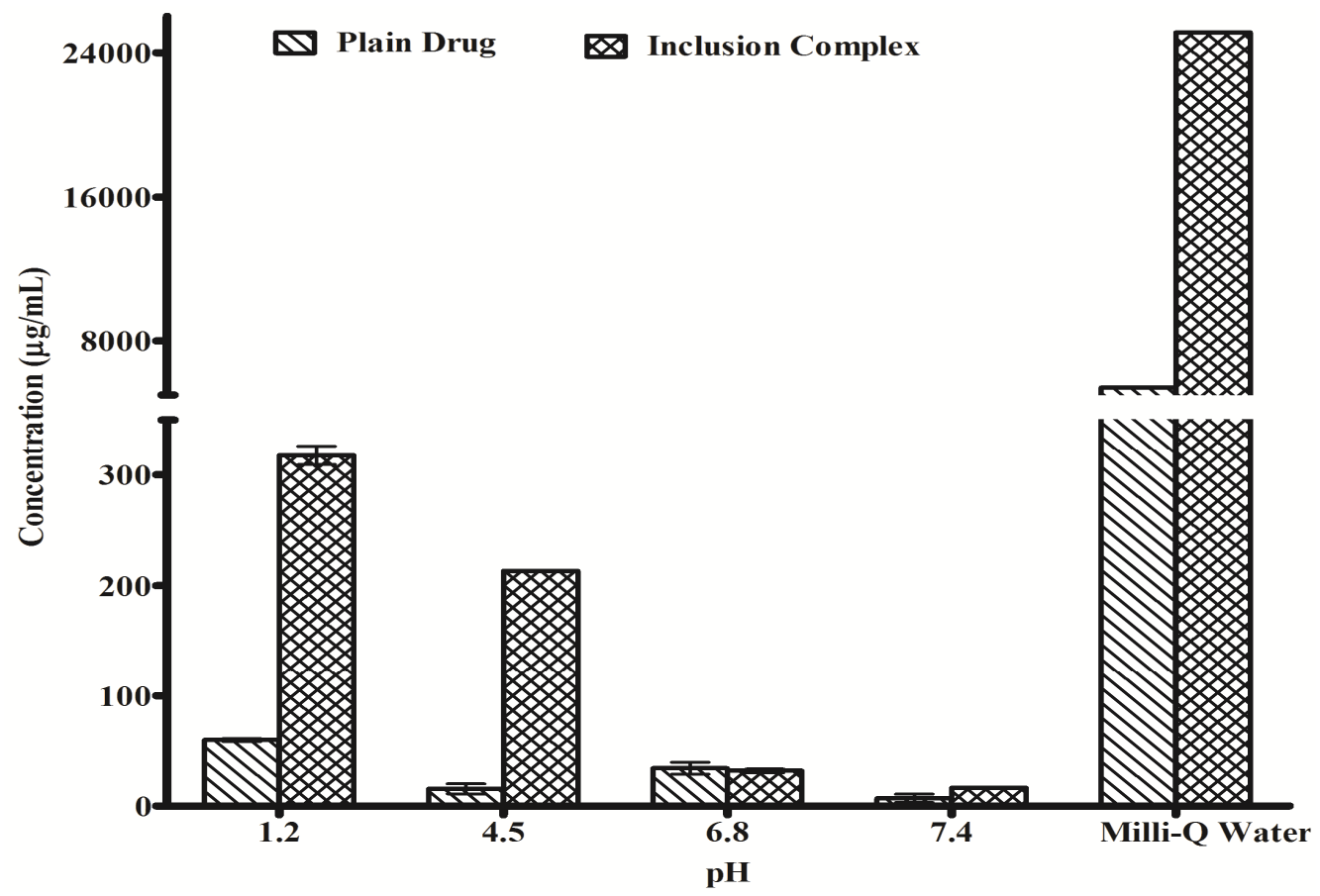

Fig 2: Graphical Representation of solubility of NM and NMß-CD (NC-02) in various media

Table 1: Comparison of pharmacokinetic parameters of NM and NM $\beta-C D$ complex in male rat

\begin{tabular}{|c|c|c|}
\hline \multirow{2}{*}{ Parameter } & \multirow{2}{*}{ Plain drug (NM) } & \multirow{2}{*}{ NM/ $\beta$-CD complex } \\
\hline & & \\
\hline$t_{\max }(h)$ & $3.000 \pm 0.00$ & $2.125 \pm 0.3146$ \\
\hline $\mathrm{C}_{\max }(\mathrm{ng} / \mathrm{ml})$ & $2031.766 \pm 649.07916$ & $3420.33 \pm 593.1910$ \\
\hline $\mathrm{AUC}_{0-\infty}\left(\mathrm{ng} \mathrm{h} \cdot \mathrm{ml}^{-1}\right)$ & $10214.16 \pm 3908.2679$ & $20321.59 \pm 4614.4340^{*}$ \\
\hline $\mathrm{AUC}_{0-\mathrm{t}}\left(\mathrm{ng} \mathrm{h} \cdot \mathrm{ml}^{-1}\right)$ & $10126.42 \pm 3919.6116$ & $19909.3 \pm 4546.1903^{\pi}$ \\
\hline Lambda Z $\left(\mathrm{h}^{-1}\right)$ & $0.4949 \pm 0.0902$ & $0.38675 \pm 0.0227$ \\
\hline Clearance $\left(\mathrm{ml} \mathrm{h}^{-1}\right)$ & $2484.338 \pm 687.8729$ & $1117.825 \pm 204.4637$ \\
\hline $\mathrm{V}_{\mathrm{d}}(\mathrm{ml} / \mathrm{kg})$ & $5775.763 \pm 2073.3297$ & $2492.103 \pm 414.5456^{\pi}$ \\
\hline $\mathrm{t}_{1 / 2}(\mathrm{hr})$. & $1.4858 \pm 0.2344$ & $1.81325 \pm 0.1192$ \\
\hline MRT (h.) & $4.103467 \pm 0.2290$ & $4.5809 \pm 0.2396$ \\
\hline Absolute bioavailability (\%) & 18.21 & 36.2 \\
\hline
\end{tabular}

${ }^{*} P \leq 0.05$; data are mean \pm standard deviation (SD)

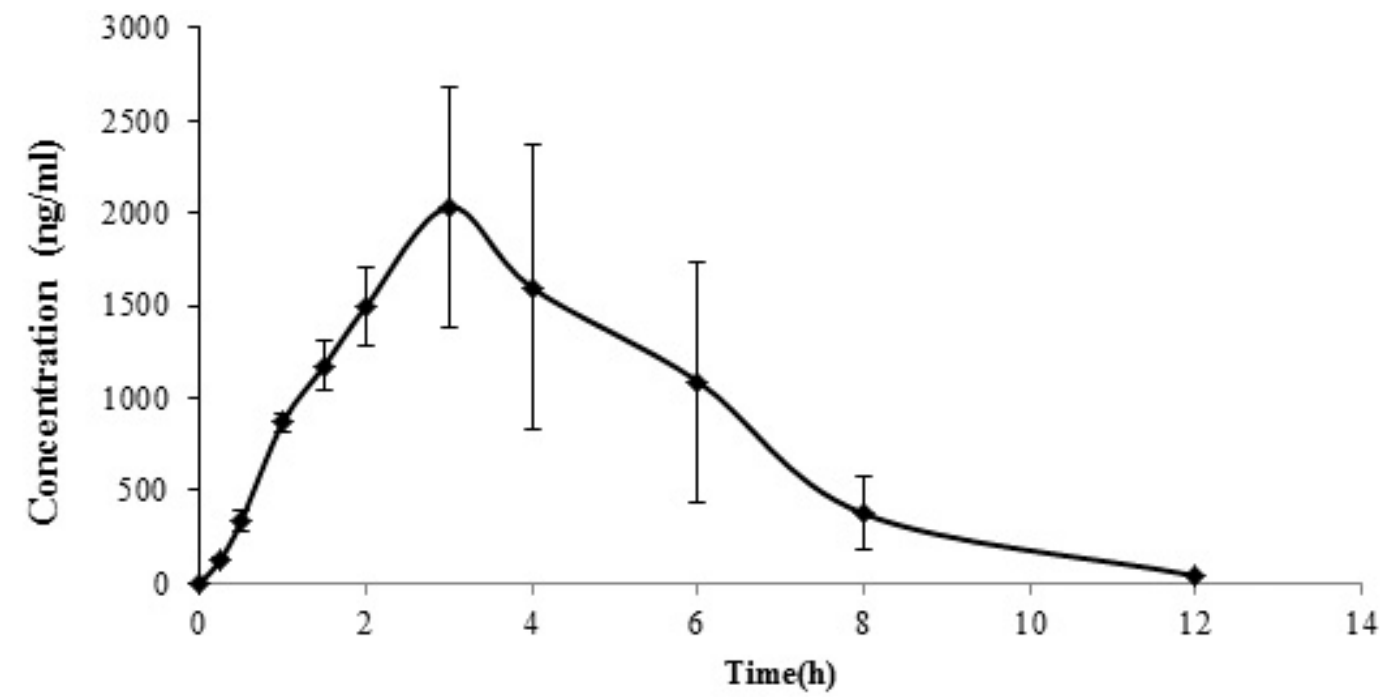

Fig 3: Mean plasma concentration - time profile of NM in the plasma of healthy male rats $(n=6)$, that were administered a single oral dose of NM 


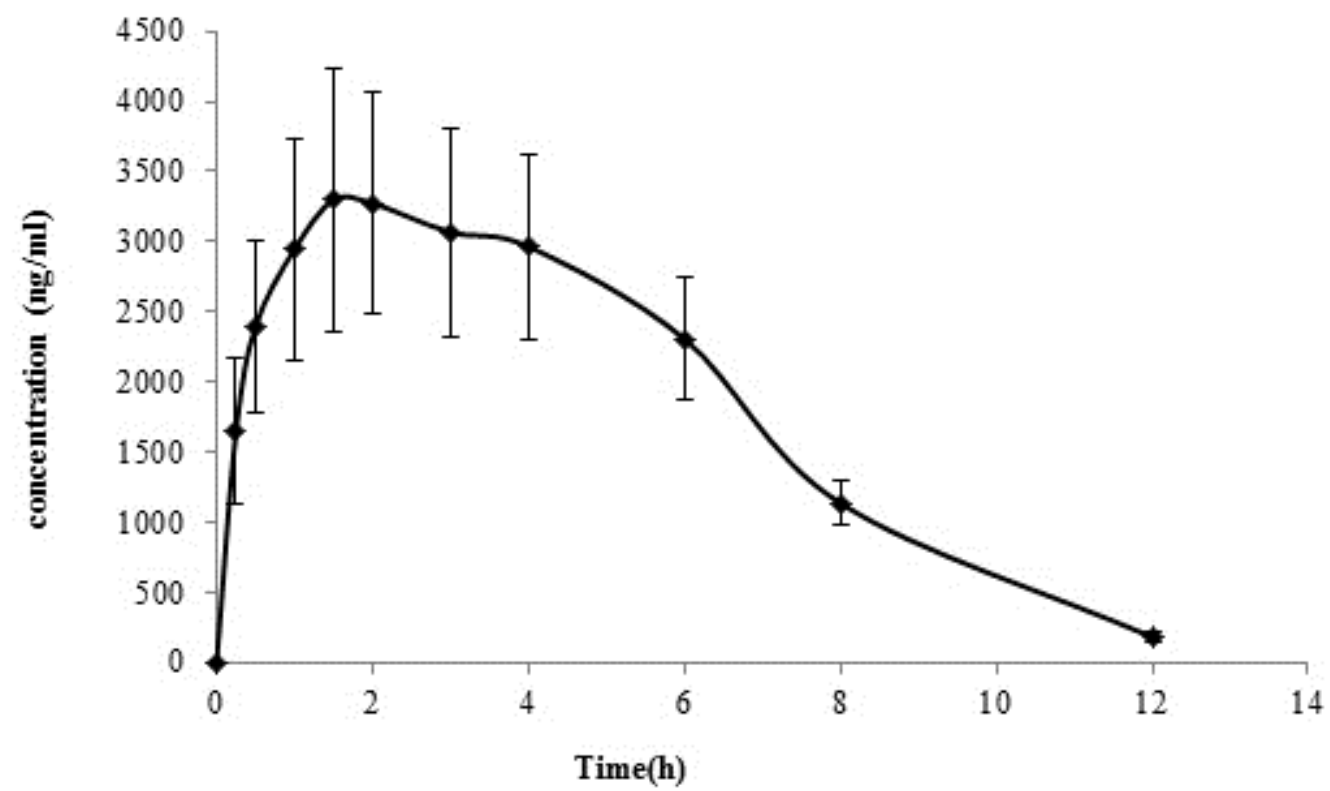

Fig 4: Mean plasma concentration - time profile of NM in the plasma of healthy male rats $(n=6)$, that were administered oral dose of NMß-CD Complex (NC-02)

The plasma drug concentration of orally administered NM suspended in $0.5 \%$ CMC increased gradually whereas the complex showed rapid increase (Table 1). The addition of $\beta-C D$ significantly improved the area under the plasma concentration-time curve (10214.16 \pm 3908.2679 to $20321.59 \pm 4614.4340 ; p \leq 0.05)$ and peak plasma concentration (2031.766 \pm 649.07916 to $3420.33 \pm 593.1910 \mathrm{ng} / \mathrm{ml} ; p \leq$ 0.05 ) of orally administered NM. This may be due to increased rate of absorption due to enhanced solubility of NM in almost all the tested buffers, which increased the dissolution rate and exposure of drug throughout the gastrointestinal tract, making it available for absorption.

The presence of $\beta-C D$ significantly reduced the total body clearance of orally administered NM compared with suspension. The $\mathrm{AUC}_{0-\infty}$ for i.v administration was $1401.634 \pm 480.0477 \mathrm{ng} / \mathrm{ml} \mathrm{h}$. The absolute bioavailability values of NM in rats administered with NM $\beta-C D$ were significantly greater $(p \leq 0.05)$ than those from the suspension. The absolute bioavailability of NM was $18.2 \%$ and had improved almost two-fold, that is $36.2 \%$, following NM $\beta-C D$ administration.

\section{DISCUSSION}

The method of preparation of drug-polymer complexes has profound influence on the physical properties of the resulting complex. Complexes obtained by solvent evaporation (NC01 ) and kneading method (NC-03) were in the form of lumps and off white in color. This may be due to processing conditions. The freeze dried product (NC-02) texture was fluffy, free flowing and white in color. Hence further evaluation was carried out using the freeze dried NM $\beta-C D$ complex. FTIR report confirmed the formation of NM $\beta$-CD complex. The IR spectra showed broadening of peak at $3379.40 \mathrm{~cm}^{-1}$ indicating interaction between the $\mathrm{OH}$ groups of cyclodextrin and NM due to formation of hydrogen bond.

The saturation solubility of drug in multimedia (Fig 2) indicates significant enhancement in solubility for the NM $\beta-C D$ complex. The dissolution profiles of inclusion complexes prepared by various methods show rapid cumulative release of $75-90 \%$ within 5 min compared to plain drug release of $40 \%$ in 90 min. It is apparent from studies reporting enhanced oral bioavailability employing cyclodextrins that enhancement in oral bioavailability is due to increase in dissolution kinetics and solubility. The classical Noyes Whitney dissolution expression is modified when cyclodextrin is present [16]. The presence of cyclodextrin in the vicinity of the dissolving drug particle enables the rate of dissolution to have a direct relation to an additional driving force: the difference in complex concentration at surface of the particle and in the bulk intestinal fluid.

The complex of a poorly soluble drug is usually more hydrophilic and soluble than the free drug. Apart from this, cyclodextrin complexes are generally amorphous. Compared to crystalline drug, amorphous drug is easily broken up by water molecules [19]. Rapid release of the drug in the first few minutes when compared to the 
pure drug could be attributed to this. The slower release for the remaining drug can be explained due to its entrapment in the host cyclodextrin inclusion complex. Apart from complexation, noninclusion phenomena such as van der Waals forces and hydrophobic interaction also contribute to formation of stable complex. Hydrogen bonds can be formed between drug molecules and hydroxyl groups on outer surface of cyclodextrin molecule [5]. The cyclodextrin molecule has glucopyranose units with hydrophilic exterior and an interior non-polar cavity. Interaction with drug leads to formation of the inclusion complex.

The results of solubility studies show highest solubility at $\mathrm{pH} 1.2$ when compared with other buffers of higher $\mathrm{pH}$. NM being a basic drug, its dissolution is favored at acidic $\mathrm{pH}$. However, highest solubility was observed in water because of its salt form physical state. Solubilisation of poorly soluble drugs complexed with cyclodextrin, because of a rise in dissolution kinetics, is often mentioned as the reason for improved drug bioavailability when complexed with cyclodextrins and used for dosing [20]. Because $\mathrm{pH}$ varies throughout the gastrointestinal tract, $\mathrm{pH}$-dependent solubility studies would benefit us greatly in assessing the oral bioavailability of NM $\beta-C D$ complexes. The variable gastrointestinal environment can alter the effect that cyclodextrin eventually has on drug solubility. As a dosage form transits through the gastrointestinal tract, the changes in physiological environment can influence the dissolution kinetics of drugs, cyclodextrins and complexes particularly if the drug ionization is affected with changes in physiological $\mathrm{pH}$ [21]. The solubility study results of the inclusion complex showed increase in all gastrointestinal buffers studied thereby ensuring improved solubility in physiological medium as well.

The pharmacokinetic studies in male Wistar rats showed a remarkable increase in the AUC of NM $\beta-C D$ complex compared to plain NM. The enhanced of bioavailability of NM, a BCS class IV drug having low solubility and low permeability, by complexation with $\beta-C D$ can be explained as follows. Cyclodextrins enhance bioavailability of insoluble drugs by increasing the drug solubility, dissolution and/or drug permeability. Cyclodextrins increase the permeability of lipophilic drugs by increasing the dissolution efficiency thereby leading to higher percentage of drug being absorbed. Because more of dissolved drug becomes available, it rapidly partitions into the membranes and gets absorbed. This justifies improvement of bioavailability of NM by $\beta-C D$ because cyclodextrins address both solubility and permeability issues.

Pharmacokinetic studies of NM by oral administration resulted in increased extent and rate of oral absorption when NM is complexed with $\beta-C D$. The increased oral bioavailability will reflect in enhanced therapeutic outcome.

\section{CONCLUSION}

Enhanced dissolution and bioavailability of NM, a BCS class IV drug, can be achieved via complexation of the drug with $\beta-C D$. There was no significant difference in dissolution profile among the inclusion complexes prepared by various methods. Pharmacokinetic studies in male Wistar rats showed distinctly different pharmacokinetic parameters of NM- $\beta-C D$ compared to NM, thereby demonstrating the enhanced bioavailability of NM and justifying the use of $\beta-C D$ inclusion.

\section{ACKNOWLEDGEMENT}

The authors thank Manipal University for providing facilities to conduct the research.

\section{REFERENCES}

1. Pai VB, Nahata MC. Nelfinavir mesylate: A protease inhibitor. Ann. Pharmacother. 1999; 33(3): 325-339.

2. Katzung BG. Basic and Clinical Pharmacology. NY: Mc Graw Hill Lange; 2002; $p 855$.

3. Lindenberg $M$, Kopp $S$, Dressman JB. Classification of orally administered drugs on the World Health Organization Model list of Essential Medicines according to the biopharmaceutics classification system. Eur. J. Pharm. Biopharm. 2004; 58: 265278.

4. Williams GC, Sinko PJ. Oral absorption of the HIV protease inhibitors: a current update. Adv Drug Deliv Rev 1999; 18; 39(1-3): 211-238.

5. Loftsson T, Brewster ME. Pharmaceutical applications of cyclodextrins. Drug solubilisation and stabilization. J. Pharm. Sci 1996; 85: 1017-1025.

6. Blanchard J, Proniuk S. Some important considerations in the use of cyclodextrins. Pharm. Res 1999; 16: 1796-1798.

7. Frijlink HW, Schoonen AJM, Lerk CF. The effects of cyclodextrins on drug absorption. In vitro observations. Int. J. Pharm. 1989; 49: 91-102.

8. Rawata S, Jain SK. Solubility enhancement of celecoxib using ß-cyclodextrin inclusion complexes. Eur. J. Pharm. Biopharm. 2004; 57: 263-267.

9. Kurkov SV, Loftsson T. Cyclodextrins. Int. J. Pharm. 2013; 453: 167-180. 
10. Hiremanth $S N$, Godge GR, Kharia AA, Vaidya VR. Studies on the Preparation, Characterization and Solubility of $\beta$-cyclodextrin-Nelfinavir Inclusion complexes. J Pharm. Res. Heal. Care 2008; 2(3): 279-284.

11. Torne SJ, Torne JS, Vavia PR, Singh SK, Kishore N. Cyclodextrin based drug delivery system of protease inhibitor-nelfinavir mesylate. J Inclu Phenom Macro 2007; (57): 689-697.

12. Anand $O, Y u L X$, Conner DP, Davit BM. Dissolution Testing for Generic Drugs: An FDA Perspective. AAPS J. 2011; 13(3): 328-335.

13. Higuchi $T$, Connors $K A$, Phase solubility techniques, in: CN Reilly (Ed), in: Advances in Analytical Chemistry and Instrumentation, Wiley-Interscience, New York, 1965, pp 117-212.

14. Sharma MC, Sharma S. Preparation, Physicochemical Characterization, Dissolution, Formulation and Spectroscopic studies of $\beta$-cyclodextrins Inclusion Complex. International Journal of Chem Tech Research 2011; 3(1): 104-111.

15. Ozkan Y, Atay T, Dikmen N, Isimer A, Aboul-Enein HY. Improvement of water solubility and in vitro dissolution rate of gliclazide by complexation with $\beta$ cyclodextrin. Pharm Acta Helv 2000; 74: 365-370.

16. Talegaonkar S, Khan AY, Khar RK, Ahmad FJ, Khan ZI. Development and Characterization of Paracetamol
Complexes with Hydroxypropyl- $\beta$-Cyclodextrin. Iran. J. Pharm. Res 2007; 6(2): 95-99.

17. Aleema $O$, Kuchekar $B$, Pore $Y$, Late $S$. Effect of $\beta$ cyclodextrin and hydroxypropyl $\beta$-cyclodextrin complexation on physicochemical properties and antimicrobial activity of cefdinir. J. Pharma. Biomed. Anal 2008; 47: 535-540.

18. Validation of Analytical Procedures: Text and Methodology.[accessed 2012 April 20] Available from http://www.ich.org/fileadmin/Public_Web_Site/ICH_Pr oducts/Guidelines/Quality/Q2_R1/Step4/Q2_R1_Guid eline.pdf

19. Rebecca L, Carrier Lee A, Miller, Ahmed I. The utility of cyclodextrins in enhancing the oral bioavailability. J. Control. Release 2007; 123: 78-99.

20. Soliman OAE, Kimura K, Hirayama F, Uekama K, ElSabbagh HM, El-Gawad AEGHA, Hashim FM. Amorphous spironolactone-hydroxypropylated cyclodextrin complexes with superior dissolution and oral bioavailability. Int. J. Pharm. 1997; 149: 73-83.

21. Savolainen J, Järvinen $K$, Taipale $H$, Jarho $P$, Loftsson $T$, Järvinen T. Co administration of a water soluble polymer increases the usefulness of cyclodextrins in solid oral dosage forms. Pharm. Res. 1998; 15(11): 1696-1701. 